\title{
Metodología de modelamiento de un sistema de transporte urbano
}

\author{
Emma Barreno Vereau, Ezilda Cabrera Gil Grados, Rosa Millones Rivalles
}

Ingeniería Industrial n. 26, 2008, ISSN 1025-9929, pp. 11-44

Resumen: En Lima, como en otras ciudades del mundo, diariamente sufrimos el problema del sistema de transporte; sin embargo, los académicos se han manifestado en muy pocas oportunidades sobre cómo hacerle frente al desafío que representa la mejora de este complejo sistema.

Este artículo presenta y desagrega el modelo de las cuatro fases en lo relativo a la demanda de transporte urbano y pone al alcance de los lectores el marco metodológico más utilizado en la planificación de este tipo de sistemas en diversas ciudades. Su finalidad es promover la discusión sobre la necesidad de adoptar una metodología y sus requisitos para enfrentar seriamente los problemas del transporte en nuestra ciudad.

Palabras clave: transporte urbano, modelos de demanda de transporte

\section{Modelling Transport}

Abstract: Like in other large cities around the world, Lima suffers everyday from public transportation problems, and experts have said very few about how to face the challenge that the improvement of this complex system represents.

This paper presents and analyzes thoroughly the classical four-stage transport model, focused on the demand for transportation services. Hence, the authors are trying to encourage the discussion about the necessity of adopting a methodological framework, as the fist step in the effort to reduce the effects of the lack of planning of Lima's transportation system on the life quality of its inhabitants.

Keywords: Urban transport systems, modeling transport 


\section{INTRODUCCIÓN}

El problema del transporte urbano es uno de los más importantes en las ciudades tanto del mundo desarrollado como de aquel en desarrollo. La congestión vehicular, el incremento de los tiempos de viaje, los accidentes y los efectos contaminantes del transporte urbano son consecuencias propias del crecimiento de las actividades económicas y del aumento de la población de las urbes, dos aspectos que originan una demanda mayor de la que el sistema de transporte existente es capaz de atender oportunamente.

Así como resultan claras las causas de los problemas del transporte urbano, también es palpable su principal efecto: el deterioro de la calidad de vida de las personas, que se evidencia en lo siguiente:

- Las variaciones en la demanda de transporte obedecen a las crecientes y diferenciadas necesidades de los pobladores de una ciudad; por ello, su comportamiento es sumamente dinámico.

- El incremento de la capacidad del sistema de transporte en las ciudades es un tema complejo, pues involucra cambios tanto en la infraestructura vial (con sus costos y plazos) como en la operación del propio servicio (unidades y reglas), ambos componentes generalmente en manos de diversos actores, cada uno incluso con objetivos diferentes dentro del mismo sistema.

Estas dos razones justifican el imperativo de analizar la demanda de transporte, modelándola y proyectándola como base para la planificación de estos sistemas.

En este sentido, el artículo presenta, desagrega y explica uno de los modelos más utilizados para el estudio y la modelación de la demanda de transporte, que ha sido el marco de trabajo en la planificación del sistema de traslado de pasajeros en diversas ciudades, incluyendo casos cercanos como los de Colombia y Chile, con la intención de promover la discusión alrededor de la metodología para el análisis y la solución de los problemas viales de la ciudad de Lima.

\section{EL MODELAMIENTO DE LOS SISTEMAS DE TRANSPORTE}

El modelo para el análisis y la planificación de sistemas de transporte urbano consiste en la representación simplificada de la interacción entre la demanda y la oferta. La demanda está representada por el 
uso de los medios de transporte por las personas, y la oferta por la red de vías y servicios de transporte.

El resultado del modelamiento del sistema de transporte urbano obtenido son indicadores de desempeño del sistema de transporte en términos de tiempo y velocidad de viaje, así como estimaciones de la emisión de contaminantes. Un adecuado modelamiento del sistema de transporte debe reflejar la conducta de los usuarios del sistema y permitir la evaluación de las condiciones dinámicas de dicha conducta.

La metodología utilizada generalmente para la construcción de este tipo de modelos comprende cuatro fases: generación de la demanda, distribución de la demanda, partición modal y asignación de la demanda a la red vial. La ejecución de estas fases emplea, básicamente, la siguiente información:

- Las características de los viajes-personas. Esta información se obtendrá a partir de encuestas de transporte, que deben guardar relación con las condiciones sociodemográficas y de uso de suelo de la zona de estudio.

- Las condiciones de la vialidad y del tránsito en la red vial de la zona de estudio.

El modelamiento del sistema de transporte urbano ha de contribuir a:

- Analizar la sensibilidad del sistema ante cambios en la demanda y la oferta, lo cual requiere proyecciones de tráfico asociadas a proyecciones demográficas y socioeconómicas, así como futuros cambios en la infraestructura vial.

- Analizar y evaluar económicamente los escenarios futuros.

Un modelo de transporte urbano debe incluir el modelamiento de tres componentes: el sistema de transporte, el sistema de actividades y el patrón de flujos.

La información requerida para la construcción del modelo es:

- El sistema de transporte relacionado con la infraestructura existente en el área de estudio, la red vial y su configuración, las características del transporte público y del sistema de gestión del tránsito, entre otros. 
- El sistema de actividades, que incluye las características demográficas y socioeconómicas de la población, así como el conjunto de actividades que ofrece el área de estudio a la población; es decir, la concentración o distribución de centros comerciales, centros de educación, atractivos turísticos, residencias, etcétera.

- El patrón de flujos, que está referido al comportamiento de los usuarios en las vías, el origen y el destino de los viajes, los horarios y las frecuencias, y el modo elegido, entre otros.

Estos tres elementos interactúan dinámicamente explicando el comportamiento del transporte urbano en el tiempo. El esquema de relaciones se muestra en la figura 1.

\section{Figura 1}

\section{Esquema de relaciones de un sistema de transporte}

(I)

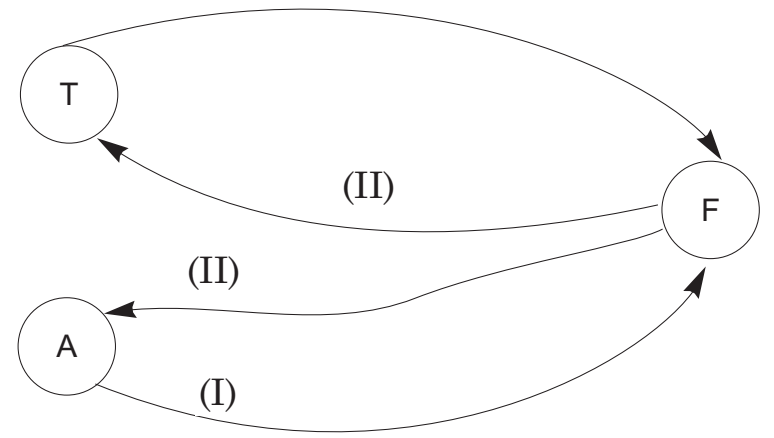

- Relaciones tipo I: originan cambios en el patrón de flujos

- Relaciones tipo II: cambios originados por modificaciones en el patrón de flujos

En el corto plazo, el sistema de transporte y el sistema de actividades determinan el patrón de flujos (relación de tipo I).

En el largo plazo, dado un patrón de flujos, producirán cambios en el sistema de actividades (relación tipo II) y estos a su vez generarán cambios en el patrón de flujos (relación tipo I). 
Estos últimos, en el mediano plazo, explicarán la demanda de cambios en el sistema de transporte (relación tipo II).

Son estas relaciones las que pueden estimarse, estudiarse y evaluarse a través de los modelos de transporte urbano, de modo que estos se constituyen en herramientas de evaluación, planificación y predicción del equilibrio del transporte urbano.

El estudio de los sistemas de transporte abarca dos ámbitos:

- El táctico, es decir, cuando el objetivo es evaluar el tráfico —el equilibrio de los flujos sobre una red vial—, dada una matriz de viajes conocida, una red con funciones de costo definidas para sus arcos y conocido el comportamiento de los usuarios, como en el caso de los estudios de impacto vial.

- El estratégico, cuando el objetivo es evaluar la consistencia entre los subsistemas de demanda (matrices de viajes) y oferta (costos resultantes en cada red), como en el caso de la evaluación de políticas o conjuntos integrales de proyectos.

Los sistemas de transporte son modelados en cuatro etapas:

- Generación y atracción de viajes.- El objetivo básico de esta etapa es predecir el número de viajes de personas o vehículos que son generados y atraídos por cada una de las zonas en que se ha desagregado el área en estudio. Esta etapa está relacionada únicamente con el número de viajes que inician y finalizan en cada zona, y no con la manera como se hacen las conexiones entre orígenes y destinos. En términos generales, se trata de explicar la forma como se generan y atraen los viajes, mediante la utilización de relaciones entre las características de los viajes y las del medio urbano.

Los modelos de generación de viajes usualmente se desarrollan de manera separada, por propósito, por modo de transporte y por hora del día. Adicionalmente, se basan en el supuesto de que los viajes son una función de tres factores:

- Patrones de usos del suelo.- Diferentes usos del suelo y distintas intensidades de uso producen diferentes características de generación de viajes. Por ejemplo, en algunos estudios se ha establecido que el $80 \%$ de los viajes se inician o finalizan en el hogar, lo cual permite resaltar la gran importancia del uso-residencia. Otros usos importantes son el uso-comercio, el uso-industria y el uso-educación. 
- Características socioeconómicas de la población.- Las principales son el tamaño de la familia, la cantidad de trabajadores y de estudiantes que hay en el hogar, el número de vehículos disponibles en el hogar, el nivel de ingreso, la edad y el sexo.

- Características del sistema de transporte.- En particular las facilidades disponibles y su nivel de accesibilidad.

- Distribución de viajes.- Los modelos de distribución agregados de viajes se usan para predecir flujos entre zonas de origen y de destino. Existen dos categorías principales de estos métodos que predominan en la planeación de transporte urbano: la de factores de crecimiento, que plantea escalar una matriz existente aplicando factores multiplicativos derivados de predicciones de producción o de atracción asociadas a las celdas de la matriz, y la del modelo gravitacional.

Los modelos gravitacionales incluyen como entrada una o más matrices de flujo y una matriz de impedancia que refleja la distancia, tiempos o costo de los viajes entre zonas, y estima el nivel futuro de producciones y atracciones. El modelo gravitacional relaciona explícitamente el flujo entre zonas con la impedancia intrazonal de los viajes. Los modelos gravitacionales son originalmente motivados porque los flujos decrecen como una función de la distancia que separa las zonas, esto es la atracción gravitacional entre dos objetos que decrece como una función de la distancia entre los objetos. Este principio es aplicado en los modelos de planeación del transporte, donde la analogía newtoniana ha sido reemplazada por la hipótesis de que los viajes entre las zonas 'i’ y 'j’ es función de los viajes originados en las zonas i y el nivel de atracción y accesibilidad de la zona j con respecto a las demás zonas.

Existen diferentes medidas de impedancia, como son: la distancia de viaje, el tiempo de viaje y su costo, así como otras funciones potenciales de impedancia que pueden ser usadas para derivar la atracción relativa de cada zona. Como una alternativa a las funciones de impedancia se puede usar otro factor de impedancia (esto es esencialmente una función de impedancia discreta que relaciona la impedancia entre zonas con la atracción entre zonas).

- Partición modal de viajes.- Los modelos de selección modal son utilizados para analizar y predecir la elección de los individuos al escoger 
los modos de transporte que son utilizados para cada tipo particular de viaje. Generalmente el objetivo es predecir la proporción o el número de viajes hechos en cada modo, principalmente predecir la proporción de los viajes atraídos por el transporte público.

Los modelos de reparto (o selección modal) pueden llevarse a cabo a nivel agregado o desagregado de zona. Los modelos a nivel agregado buscan predecir las cuotas zonales de viajes por modo y se calculan de manera típica por medio de la utilización de cuotas según modo, por pares de origen-destino y de promedios de datos demográficos por zona. Los modelos desagregados se basan en datos a nivel individual obtenidos a través de la aplicación de diversos tipos de encuestas. A nivel individual la elección es discreta, es decir, una persona elige una entre un conjunto de alternativas modales. Los modelos logit se estiman con frecuencia sobre la base de datos a nivel individual y se elaboran pronósticos basados en variables agregadas explicativas.

- Asignación de viajes.- Los modelos de asignación aportan elementos para identificar la oferta en el proceso de planeación del transporte. El sistema de la red, en el caso de transporte público, y las características de los servicios ofrecidos, tales como frecuencia y capacidad, representan los elementos principales del lado de la oferta en el transporte.

El lado de la oferta consta de una red de vías representada por los enlaces y sus costos. Los costos son una función de un número de atributos asociados con los arcos, por ejemplo, la distancia, la velocidad de flujo libre, la capacidad y una relación velocidad-flujo. El lado de la demanda consta de una indicación del número de viajes, por par origen-destino y modo para un nivel dado de servicio. En este contexto, uno de los elementos principales que define los niveles de servicios es el tiempo de viaje, pero muchas veces los costos monetarios (tarifas, combustible), las atracciones y el confort para el público también pueden ser relevantes.

Si el nivel real del servicio ofrecido por la red de transporte llega a ser más bajo de lo estimado, entonces se podría esperar una reducción en la demanda y tal vez un cambio a otros destinos, modos y horas. La relación velocidad-flujo (o la generalizada de costo-flujo) es importante como relación entre el uso de la red y el nivel de servicio que puede ofrecer. 
En el caso de un sistema de transporte se puede ver que un equilibrio tiene lugar a varios niveles. El más sencillo es el equilibrio en la red de caminos donde los viajeros de una matriz fija de viaje buscan rutas para minimizar sus costos de viaje (los tiempos). Esto resulta en la prueba de rutas alternativas, explorando nuevas y tal vez se acostumbran a un modelo relativamente estable después de mucho ensayo y error. Esta asignación de viajes a rutas produce un modelo de flujos de trayectoria y arco, los cuales, se puede decir, están en equilibrio cuando los viajeros ya no pueden encontrar rutas mejores para sus destinos: viajan en las mejores rutas disponibles. Este es el equilibrio de la red de caminos.

\section{Figura 2}

\section{Esquema del modelo de cuatro etapas}
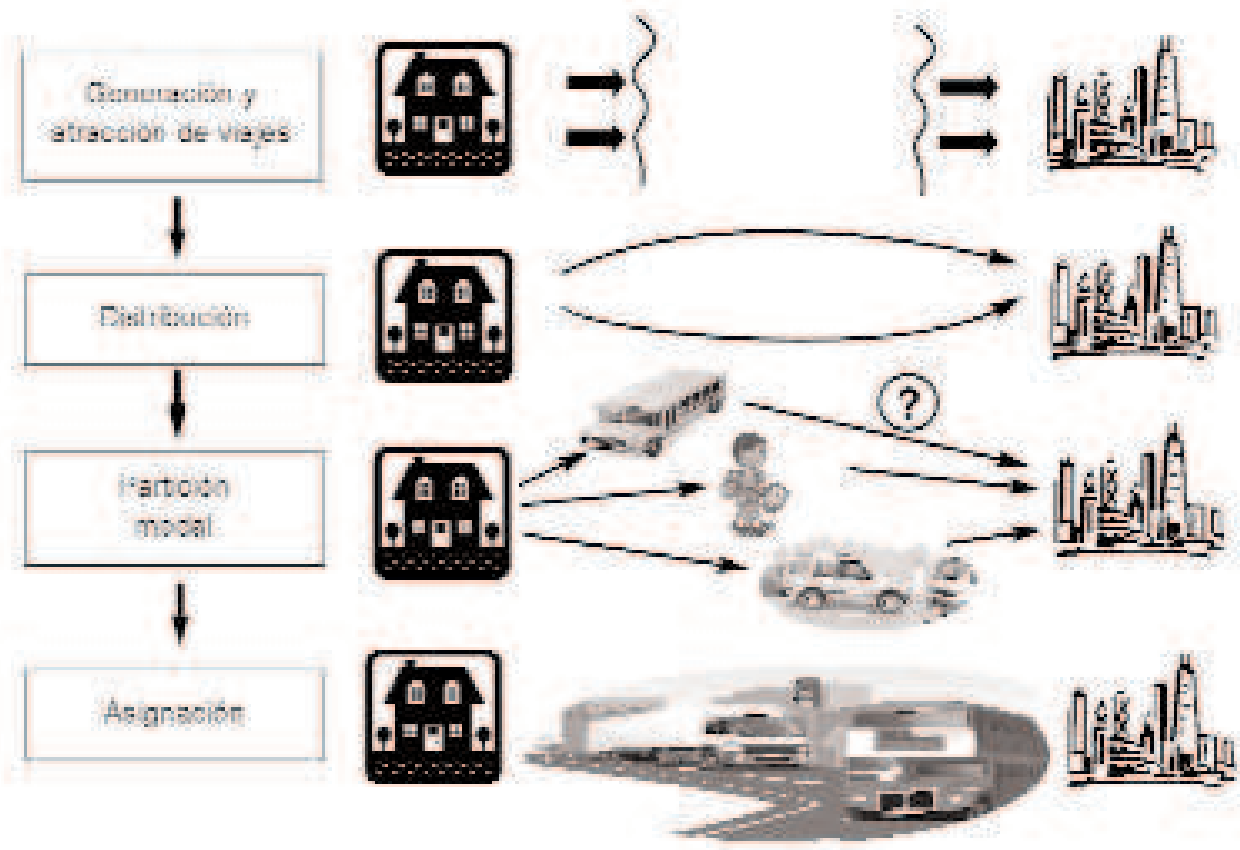

Elaboración propia. 


\section{METODOLOGÍAS}

$\mathrm{El}$ análisis de los sistemas de transporte requiere la construcción de modelos bajo una de dos metodologías: secuencial y de equilibrio simultáneo. Ambas recurren al clásico modelo de las cuatro fases o etapas.

\subsection{Metodología secuencial}

Los modelos más usados resuelven secuencialmente cada una de las cuatro etapas del modelo clásico de transporte, es decir, cada una de las etapas, y los resultados obtenidos son utilizados en la etapa siguiente sin que exista una retroalimentación entre las etapas. En este modelo se supone que los usuarios de un sistema de transporte realizan una serie de elecciones que caracterizan sus viajes:

- De dónde a dónde viaja (generación y atracción de viajes)

- El modo de viaje (partición modal)

- La ruta que eligen (asignación de viajes).

Figura 3

Esquema del modelo secuencial ${ }^{1}$

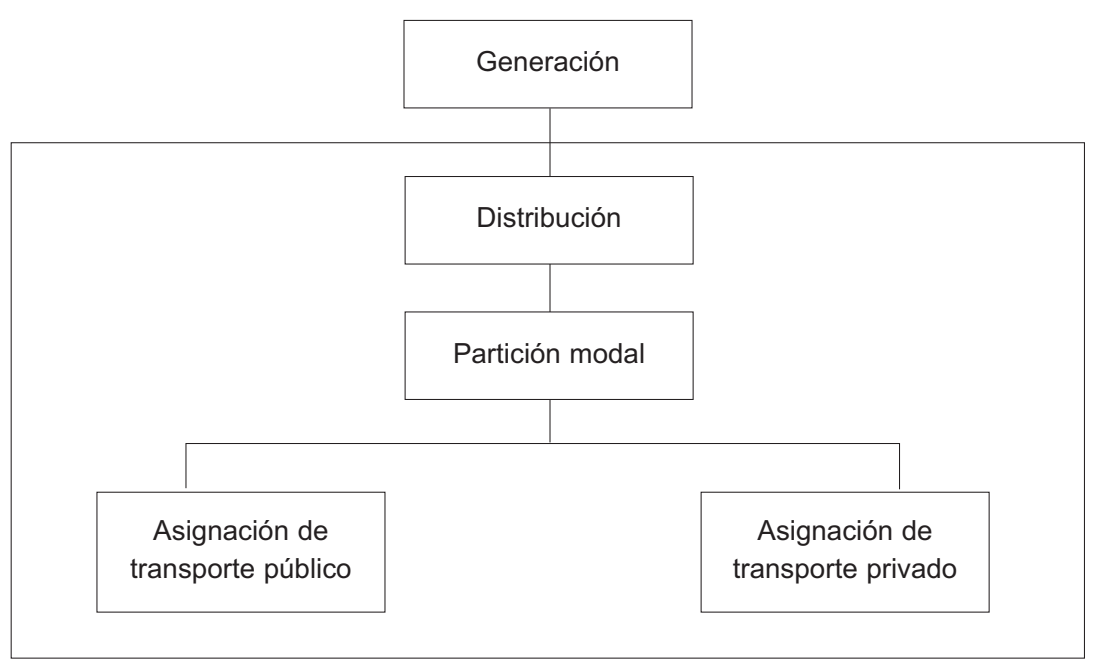

1 Comisión de Planificación de Inversiones en Infraestructura de Transporte. Metodología para análisis de sistemas de transporte en grandes ciudades y ciudades de tamaño medio. Santiago de Chile, 1998. 
Estas elecciones permitirán determinar las características operacionales del sistema de transporte.

\subsection{Metodología del equilibrio simultáneo}

En la metodología de equilibrio simultáneo se resuelven las etapas de demanda (generación, distribución y partición modal) y de oferta (asignación) en forma simultánea, se supone que tanto la demanda como la oferta se influyen mutuamente y por tanto no pueden ser determinadas separadamente. Este supuesto implica la construcción de un modelo matemático más complejo, cuya solución representa el estado de equilibrio oferta-demanda del sistema de transporte y caracteriza su operación típica (véase figura 4).

La elección del enfoque metodológico depende de las características operacionales del sistema de transporte, la complejidad y el tamaño, que pueden expresarse básicamente en términos de la congestión sobre la red vial. Así, en ciudades de tamaño medio, dados los requerimientos técnicos y presupuestales del enfoque de equilibrio simultáneo, no es adecuado.

\section{REQUERIMIENTOS DE INFORMACIÓN, SU OBTENCIÓN Y TRATAMIENTO}

Los diversos modelos de la demanda de transportes necesitan de información de entrada de diversa índole para la obtención del producto final de cada modelo. La adecuada definición de la información repercutirá en la calidad de los resultados. A continuación se presenta la información de entrada necesaria en cada una de las etapas del modelo de transporte urbano.

La información de entrada para el modelo de generación y atracción de viajes es la encuesta viaje-persona, y los datos socioeconómicos y de accesibilidad (uso de suelo).

La encuesta viaje-persona presenta tres partes principales: hogares, personas y viajes. En relación con la información de hogares se recaban, entre otros, los siguientes datos: número de residentes en el hogar; condición de la vivienda: régimen de tenencia; tipo de vivienda, antigüedad y número de habitaciones; ingreso mensual del hogar; tenencia de vehículos y tenencia de muebles. En relación con las perso- 
Figura 4

Esquema del modelo de equilibrio ${ }^{2}$

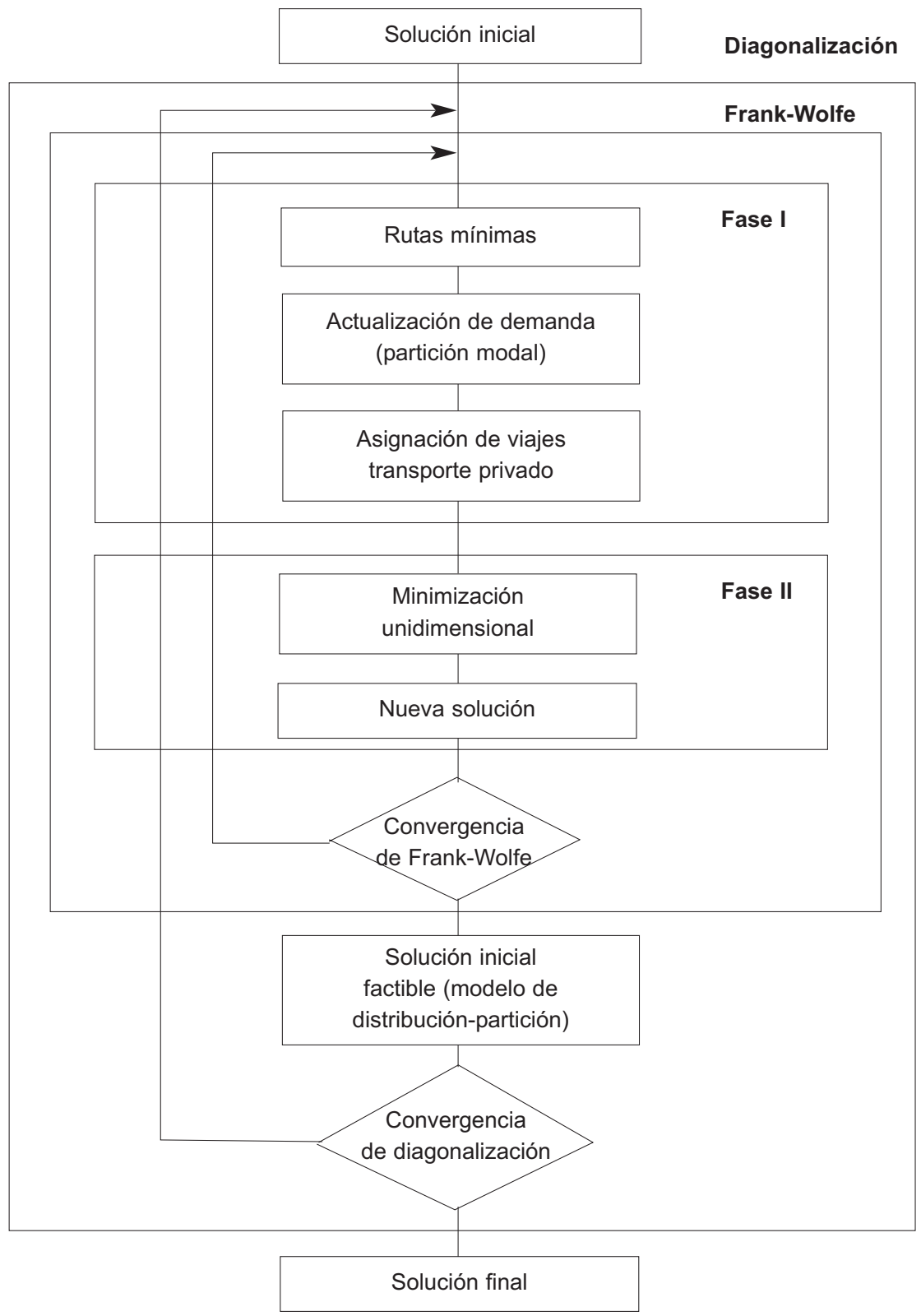

2 Comisión de Planificación de Inversiones en Infraestructura de Transporte. "Metodología para análisis de sistemas de transporte en grandes ciudades y ciudades de tamaño medio". Santiago de Chile, 1998. 
nas se pregunta sobre sexo, edad, si hay discapacidad, ocupación, actividad económica, posesión de licencia de conducir, ubicación del centro de trabajo y ubicación del centro de estudios. Respecto de los viajes, la información de interés es la siguiente: origen del viaje, hora de salida, destino del viaje, hora de llegada, propósito del viaje y medio de transporte.

Los datos socioeconómicos se deben obtener principalmente de los censos nacionales de población y vivienda. Estos datos deben brindar la futura proyección de la población a mediano (5 años) y largo plazo (20 años), con la finalidad de disponer de un marco socioeconómico para el análisis de la demanda de transporte en el futuro en el área de estudio. Los datos socioeconómicos actuales y los de las proyecciones se han de distribuir según las zonas de tránsito designadas.

Esta selección debe realizarla un especialista en el área, quien debe presentar la siguiente información: número de hogares, habitantes de seis años a más; total de habitantes; población económicamente activa (PEA) de los sectores primario, ${ }^{3}$ secundario y terciario que residen en la zona; PEA de los sectores primario, secundario y terciario que trabajan en la zona; estudiantes de primaria/secundaria, de educación superior y ocupacional que residen en la zona; y estudiantes de primaria/secundaria, de educación superior y ocupacional que estudian en la zona.

Los diferentes usos del suelo y las distintas intensidades de uso producen diversas características de generación de viajes. La mayor importancia la tiene el uso residencial, que se suele medir en hectáreas, número de viviendas o número de residentes. Otros usos del suelo son para actividades comerciales, industriales y educativas, que se expresan en número de puestos disponibles o de área total utilizada.

La información de entrada para el modelo de distribución de viajes es el total de viajes generados y atraídos por zona, y los costos generalizados de viaje.

3 Sector primario: actividades de agricultura, ganadería, caza, pesca, silvicultura y minería. Sector secundario: actividades de la industria manufacturera y la construcción. Sector terciario: actividades de comercio y servicios básicos. 
El total de viajes generados y atraídos por zona se refiere al número total de viajes producidos, según propósito de los usuarios de cada categoría en cada una de las zonas de tránsito y los costos generalizados de viaje son una medida o factor de impedancia que permite determinar adecuadamente los viajes generados y atraídos por cada zona.

La información de entrada para el modelo de partición modal es: distribución de viajes entre zonas, viajes generados en la zona ' $y$ ' atraídos por la zona 'j’, información socioeconómica a nivel individual y costos modales de viaje.

La distribución de viajes es la elección que los individuos harán al escoger los modos de transporte que son utilizados para cada tipo particular de viaje. Generalmente el objetivo es predecir la proporción o el número de viajes realizados en cada modo, principalmente predecir la proporción de los viajes atraídos por el transporte público.

La información socioeconómica individual se encuentra referida a la elección de un modo de viaje, ya que está estrechamente relacionado con el valor que le otorga cada individuo al tiempo que empleará en usar cada modalidad de transporte, así como con su nivel socioeconómico. Cada modo de viaje tendrá asociado un costo de viaje que influirá en su elección.

La información de Sahdé para el modelo de partición modal es: distribución de viajes entre zonas por modo, viajes por cada modo generados en la zona 'i' atraídos por la zona 'j', y la red de transporte público y privado con relaciones flujo-velocidad.

La distribución de viajes entre zonas por modo de viaje es la cantidad o proporción de viajes entre zonas que se realizarán según cada tipo de modo de viaje.

La distribución de viajes se encuentra relacionada con el nivel socioeconómico de los individuos, así como de sus preferencias declaradas.

El levantamiento de información para el modelamiento de un sistema de transporte es un proceso de vital importancia, que exige la realización de varias encuestas para conocer las características del transporte. En la tabla 1 se detallan las encuestas recomendadas. 
Tabla 1

Esquema de encuestas de transporte

\begin{tabular}{|c|c|c|c|c|}
\hline $\mathbf{N}^{\circ}$ & Encuesta & Objetivo & Cobertura & Método \\
\hline 1 & $\begin{array}{l}\text { Encuesta de viaje } \\
\text { persona }\end{array}$ & $\begin{array}{l}\text { Perfil socioeconómi- } \\
\text { co e información de } \\
\text { viajes de residentes }\end{array}$ & $\begin{array}{l}\text { Recomendación del } \\
\text { número de hogares } \\
\text { encuestados en el } \\
\text { área del estudio } \\
(2,0 \%)\end{array}$ & $\begin{array}{l}\text { Entrevistas directas } \\
\text { a todos los miembros } \\
\text { de las familias selec- } \\
\text { cionadas }\end{array}$ \\
\hline 2 & $\begin{array}{l}\text { Conteos en línea } \\
\text { cordón }\end{array}$ & $\begin{array}{l}\text { Volumen de tránsito e } \\
\text { información de viaje } \\
\text { de no residentes }\end{array}$ & $\begin{array}{l}\text { Estaciones en la } \\
\text { frontera del área del } \\
\text { estudio, incluyendo } \\
\text { el aeropuerto }\end{array}$ & $\begin{array}{l}\text { Conteos de tránsito } \\
\text { en } 17 \text { o } 24 \text { horas, en- } \\
\text { trevistas directas de } \\
\text { pasajeros y el } \\
\text { conductor, y obser- } \\
\text { vación de la ocupa- } \\
\text { ción del vehículo }\end{array}$ \\
\hline 3 & $\begin{array}{l}\text { Conteos en línea } \\
\text { cortina }\end{array}$ & $\begin{array}{l}\text { Volumen de tránsito } \\
\text { y ocupación del ve- } \\
\text { hículo en la línea } \\
\text { cortina }\end{array}$ & $\begin{array}{l}\text { Estaciones a lo largo } \\
\text { de las líneas cortina } \\
\text { que se establezcan }\end{array}$ & $\begin{array}{l}\text { Conteos de tránsito } \\
\text { de } 4 \text { o } 24 \text { horas y ob- } \\
\text { servación de la ocu- } \\
\text { pación del vehículo }\end{array}$ \\
\hline 4 & $\begin{array}{l}\text { Volumen de conteo } \\
\text { del tránsito }\end{array}$ & $\begin{array}{l}\text { Volumen de tránsito } \\
\text { y ocupación del ve- } \\
\text { hículo en vía troncal }\end{array}$ & $\begin{array}{l}\text { Estaciones para con- } \\
\text { teos de } 24 \text { horas y } \\
\text { estaciones para con- } \\
\text { teos de } 4 \text { horas du- } \\
\text { rante la hora pico de } \\
\text { la mañana }\end{array}$ & $\begin{array}{l}\text { Conteos de tránsito } \\
\text { de } 17 \text { o } 24 \text { horas y } \\
\text { observación de la } \\
\text { ocupación del ve- } \\
\text { hículo }\end{array}$ \\
\hline 5 & $\begin{array}{l}\text { Encuesta de prefe- } \\
\text { rencias declaradas }\end{array}$ & $\begin{array}{l}\text { Preferencia declara- } \\
\text { da del modo esco- } \\
\text { gido }\end{array}$ & $\begin{array}{l}\text { Hogares encuesta- } \\
\text { dos cubriendo todos } \\
\text { los niveles econó- } \\
\text { micos }\end{array}$ & $\begin{array}{l}\text { Entrevista directa a } \\
\text { miembros seleccio- } \\
\text { nados }\end{array}$ \\
\hline 6 & $\begin{array}{l}\text { Encuesta de } \\
\text { destino }\end{array}$ & $\begin{array}{l}\text { Características del } \\
\text { modo escogido en el } \\
\text { punto de destino }\end{array}$ & $\begin{array}{l}\text { Personas encuesta- } \\
\text { das en destinos de } \\
\text { actividades como } \\
\text { empresas, mercados, } \\
\text { colegios, etc. }\end{array}$ & $\begin{array}{l}\text { Entrevista directa a } \\
\text { personas seleccio- } \\
\text { nadas }\end{array}$ \\
\hline
\end{tabular}

(continúa) 
(continuación)

\begin{tabular}{|c|c|c|c|c|}
\hline $\mathbf{N}^{\circ}$ & Encuesta & Objetivo & Cobertura & Método \\
\hline 7 & $\begin{array}{l}\text { Encuesta de veloci- } \\
\text { dad de viaje }\end{array}$ & $\begin{array}{l}\text { Velocidad de viaje en } \\
\text { las principales sec- } \\
\text { ciones de las vías }\end{array}$ & $\begin{array}{l}\text { Observación durante } \\
\text { las horas pico y ho- } \\
\text { ras valle en corredo- } \\
\text { res principales }\end{array}$ & $\begin{array}{l}\text { Tres viajes ida y } \\
\text { vuelta en el periodo } \\
\text { de tiempo por ruta } \\
\text { con el método de } \\
\text { vehículo flotante }\end{array}$ \\
\hline
\end{tabular}

8 Encuesta de trans- Características del Estaciones de con- Conteo de tránsito y porte de carga flujo de bienes y teo las 24 horas, entrevistas directas carga estaciones para con- al conductor. Entreteos de 17 horas y vistas en empresas empresas de trans- de transporte selecporte principales pa- cionadas ra las entrevistas

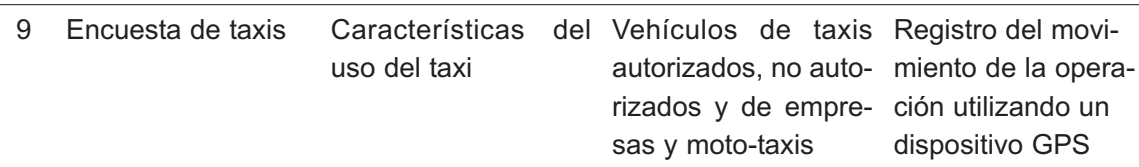

10 Inventario vial Estructura de las Puntos en las mis- Observación y medisecciones en las vías mas estaciones de ción en el punto típiprincipales conteo de tránsito co de cada sección

\begin{tabular}{llrl}
\hline Encuesta de esta- & Infraestructura de & Instalaciones de es- & Entrevista directa \\
cionamientos & estacionamiento y & tacionamiento públi- & con administradores \\
& características de la & co y privado existen- & para la elaboración \\
demanda de estacio- & tes en distritos cen- & del inventario, y con- \\
& namiento & trales, y estaciones & teo de demanda con \\
& & para la encuesta de & la metodología de \\
& demanda & "conteo de placa de \\
& & matrícula"
\end{tabular}

Fuente: Elaboración propia. 
En la figura 5 se presenta un esquema del proceso de toma de información.

Figura 5

Proceso de toma de información

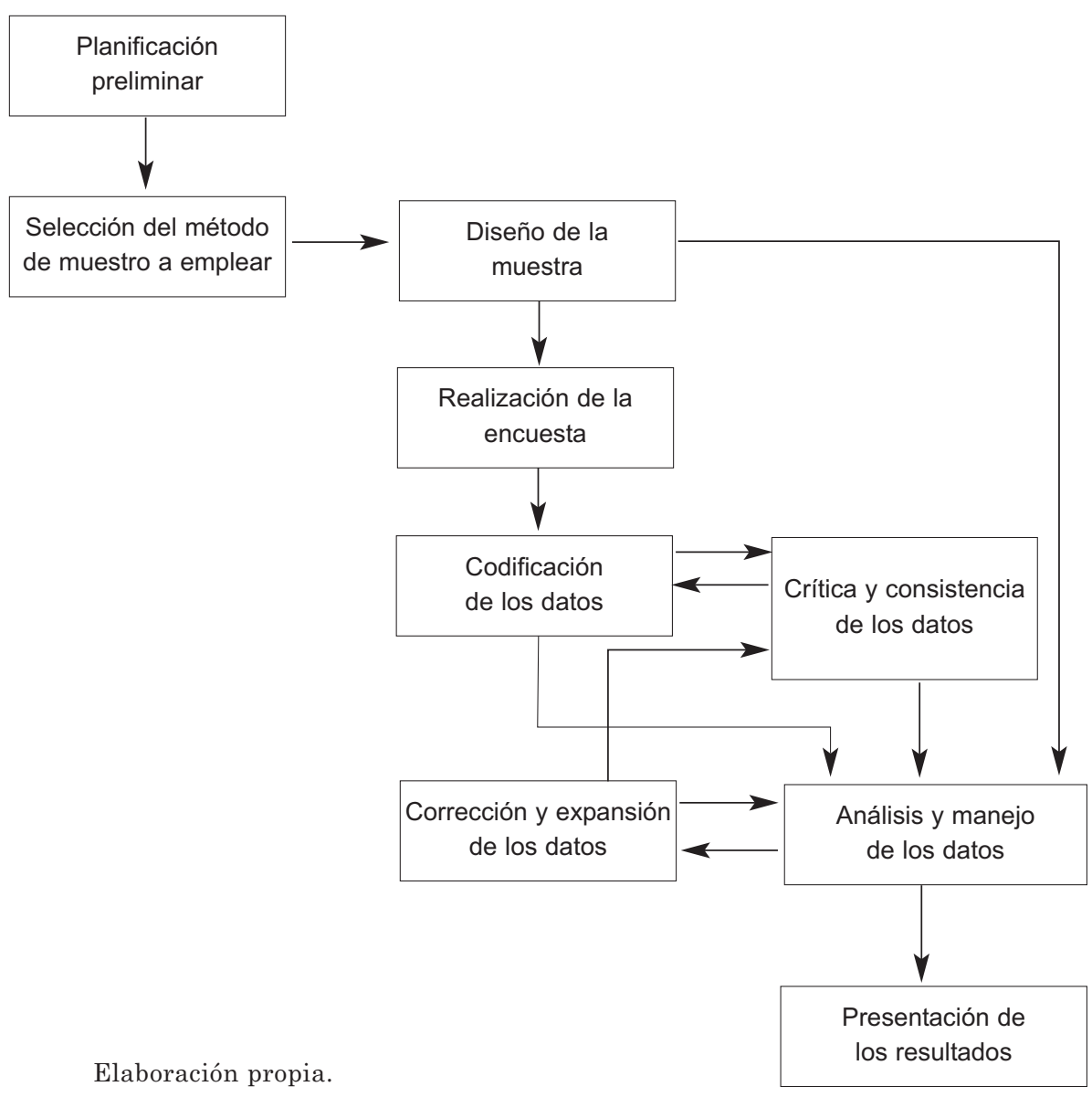

Se propone aquí una metodología para la aplicación de la encuesta viaje-persona, que es la más importante. Una de las actividades fundamentales para la ejecución de la encuesta es la denominada "operación de campo", que es el conjunto de tareas interrelacionadas entre sí y que tendrán como objetivo la recopilación de la información de los 
hogares en forma eficiente y oportuna, para lo cual es necesario que su planeamiento, programación, ejecución y control se realice en forma integrada y con ello se logren los resultados esperados.

Los objetivos de la encuesta son:

- Objetivo general: Establecer el perfil socioeconómico de los hogares y sus residentes, así como obtener información para determinar patrones de movilidad entre las zonas de tránsito establecida, para usuarios de transporte público y privado, en las principales vías de interés para el estudio.

- Objetivos específicos: Se plantearon de acuerdo con las tres partes que componen la encuesta y están referidos específicamente a obtener información de la vivienda y del número de ocupantes; conocer la ocupación y las actividades de las personas residentes en la vivienda; conocer dónde laboran o estudian; y obtener información sobre el número de viajes diarios que realizan los residentes según propósitos de viaje y modos de transporte.

La población de estudio se encuentra definida como el conjunto de personas de seis años a más residentes en las viviendas de las zonas de tránsito establecidas.

La muestra es probabilística, estratificada y bietápica. Probabilística porque las unidades serán seleccionadas mediante métodos al azar, lo que permite efectuar inferencias a la población en base a la teoría de probabilidades. Estratificada porque las unidades serán agrupadas en zonas de tránsito, lo que permite reducir la variabilidad de las estimaciones. Bietápica porque se encuentra compuesta por dos etapas: la primera utiliza una selección sistemática con probabilidad proporcional al tamaño (número de viviendas de cada conglomerado) y la segunda consiste en la selección de las viviendas sistemática simple al azar.

Se han definido unidades de muestreo primarias y secundarias. Las primarias son unidades de muestreo a los conglomerados; cada conglomerado tendrá en promedio 80 viviendas contenidas en cada zona de tránsito. Las secundarias son las viviendas particulares contenidas en cada conglomerado.

Para la ejecución de la encuesta de viajes de personas (origen y destino), de acuerdo con los requerimientos establecidos, se recomienda un 
tamaño de muestra de aproximadamente $2,0 \%$ de la población, distribuidos de acuerdo a la densidad poblacional de las zonas de tránsito.

De acuerdo con las preguntas a formularse en la encuesta viajepersona, se pueden obtener ratios e indicadores univariados.

- De los hogares.- Número promedio de residentes, antigüedad promedio de la vivienda, número promedio de habitaciones, ingreso promedio mensual del hogar y porcentajes de los niveles de educación del jefe del hogar, de los tipos de régimen de tenencia de la vivienda, de los tipos de vivienda, de hogares que poseen vehículos y de posesión de diferentes tipos de muebles.

- De las personas.- Edad promedio y porcentaje de personas de cada sexo, de personas con tenencia de discapacidad, de los tipos de ocupación, de los tipos de actividad económica, de personas con posesión de licencia de conducir, de las ubicaciones del centro de trabajo y de las ubicaciones del centro de estudios.

- De los viajes.- Tarifa promedio de estacionamiento y porcentaje de las zonas de origen del viaje, de los lugares de origen, de las horas de salida, de las zonas de destino del viaje, de los lugares de destino, de las horas de llegada, de los tipos de propósitos del viaje, de los medios de transporte, de los viajes realizados manejando el auto en que viajó, de los lugares de estacionamiento del auto en que viajó y de los lugares de estacionamiento en que se efectuó algún pago.

Enseguida se brinda una descripción de las metodologías que se utilizan en cada una de las tres primeras etapas del modelo de cuatro etapas, que son precisamente las que analizan la demanda de viajes. El objetivo básico de la primera etapa de la modelación del transporte, generación y atracción de viajes, es predecir el número de viajes de personas o vehículos que son generados y atraídos por cada una de las zonas en que se ha desagregado el área de estudio. Esta etapa del proceso de planeación del transporte está relacionada únicamente con el número de viajes que inician y finalizan en cada zona, y no con la manera como se hacen las conexiones entre orígenes y destinos de viajes.

En la figura 6 se aprecia un esquema que muestra los datos de entrada, las técnicas analíticas y los resultados obtenidos en la aplicación del modelo de generación y atracción de viajes. 
Figura 6

Esquema del modelo de generación y atracción de viajes

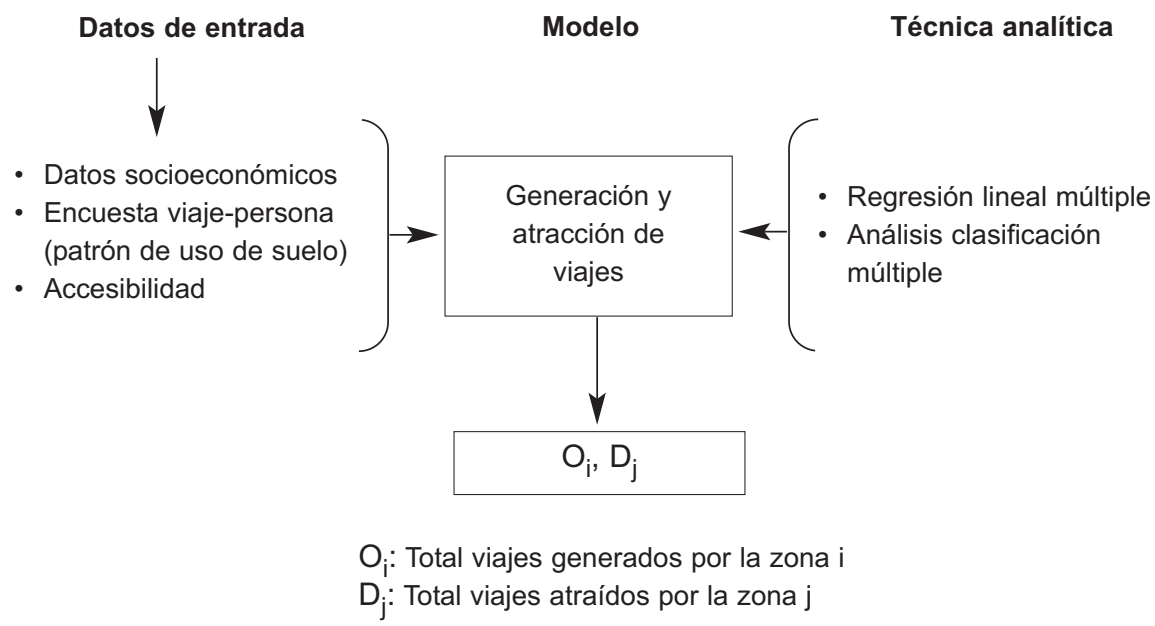

Elaboración propia.

En términos generales, se trata de explicar la forma como se generan y atraen los viajes, mediante la utilización de relaciones entre las características de los viajes y las del medio urbano. Los modelos de generación de viajes generalmente se desarrollan de manera separada, por propósito, por modo de transporte, y por hora del día. Adicionalmente, se basan en el supuesto de que los viajes son una función de tres factores:

- Características socioeconómicas de la población.- Las principales características normalmente consideradas son el tamaño de la familia, la cantidad de trabajadores y de estudiantes en el hogar, el número de vehículos disponibles en el hogar, el nivel de ingreso y la estructura de edades y sexo.

- Patrones de usos del suelo.- Diferentes usos del suelo y distintas intensidades de uso producen diferentes características de generación de viajes. El rango de usos es muy amplio y por tanto deben considerarse los más importantes. Se tiene por ejemplo que algunos estudios han establecido que del orden del $80 \%$ de los viajes se inician o finalizan en el hogar, lo cual permite resaltar la gran im- 
portancia del uso residencial, que se suele representar en términos de hectáreas utilizadas, número de viviendas o número de personas residentes. Otros usos importantes son comercio, industria y educación, que se expresan en número de puestos disponibles o de área total utilizada.

- Características del sistema de transporte.- En particular las facilidades disponibles y su nivel de accesibilidad.

Idealmente, debiera estimarse un vector de orígenes y un vector de destinos por cada propósito y categoría de demanda, pero en la práctica la clasificación por categoría de demanda no siempre es posible. Dado que estas se definen a partir de los niveles de ingresos económicos y la tasa de motorización de los hogares (vehículos/persona), es fácil obtener la categorización de los orígenes (producción de viajes) cuando los viajes se originan en el hogar, lo cual es una característica de la mayoría de los viajes en el período punta de la mañana.

Sin embargo, durante estos mismos períodos, la mayoría de los viajes se realizan hacia lugares distintos del hogar, por lo que una eventual categorización de los destinos (atracciones de viajes) resultaría arbitraria en el mejor de los casos.

Considerando lo anterior, el modelo propuesto supone que solo los orígenes son clasificables por propósito-categoría y los destinos, en cambio, son clasificables solo por propósitos de viaje. Así, el modelo de transporte recibe como datos de entrada un vector origen por cada propósito de viaje y por cada categoría de demanda $\left(\mathrm{O}_{i}^{\mathrm{pn}}\right)$ y un vector destino por cada propósito de viaje, en el que todas las categorías de demanda están agrupadas $\left(D_{j}^{p}\right)$. Además, debe cumplirse:

$$
\sum_{i} \sum_{p} \sum_{n} O_{i}^{p n}=\sum_{j} \sum_{p} D_{j}^{p}
$$

Donde:

$$
\begin{aligned}
& \mathrm{O}_{\mathrm{i}}^{\mathrm{pn}} \text { : Número de viajes generados en la zona } \boldsymbol{i} \text {, de la categoría } \boldsymbol{n}, \\
& \quad \text { con propósito } \boldsymbol{p} . \\
& \mathrm{D}_{\mathrm{j}}^{\mathrm{p}}: \text { Número de viajes atraídos por la zona } \boldsymbol{j} \text {, con propósito } \boldsymbol{p} .
\end{aligned}
$$


Por razones metodológicas, las generaciones de viajes (orígenes) son modeladas independientemente de las atracciones de viajes (destinos), aunque evidentemente sus resultados deben ser consistentes, tal como se desprende de la expresión (5.1). Por otra parte, dado el mayor desarrollo conceptual de los modelos de generación de viajes, habitualmente se tiende a confiar más en sus resultados y, por lo tanto, normalmente se ajustan las atracciones a las generaciones de viajes.

Para realizar este ajuste se debe calcular un factor de corrección para cada propósito de viaje, de la siguiente manera:

$$
f_{p}=\frac{\sum_{i} \sum_{n} O_{i}^{p n}}{\sum_{j} D_{j}^{p}}
$$

Luego se multiplica dicho factor por los componentes del vector de destinos del propósito correspondiente, obteniéndose los valores ajustados:

$$
D_{j}^{p(a)}=f_{p}^{*} D_{j}^{p}
$$

Dos tipos de modelos se utilizan para explicar la generación de viajes: regresión lineal y análisis por categoría. La elección de uno u otro depende de las características de los viajes cuyos orígenes o destinos se desea explicar. Si bien los modelos de análisis por categoría son conceptualmente más adecuados, su ámbito de aplicación se reduce básicamente a aquellos viajes originados en el hogar. Por otra parte, aunque los modelos de regresión lineal no son especialmente adecuados para explicar la generación de viajes, en casos tales como las atracciones de viajes y las generaciones de viajes no originados en el hogar, suelen ser la única herramienta metodológica disponible para estudiarlos.

Las generaciones de viajes más relevantes pueden diferenciarse en tres tipos:

- Generación de viajes basados en el hogar de ida (bhi).

- Generación de viajes basados en el hogar de retorno (bhr).

- Generación de viajes no basados en el hogar (nbh). 
El primero será estimado mediante modelos de Análisis de Clasificación Múltiple (ACM), en tanto que para el segundo y el tercero se pueden utilizar modelos de regresión lineal múltiple (RLM).

Los orígenes de una zona pueden ser expresados como sigue:

$$
\mathrm{O}_{\mathrm{i}}^{\mathrm{pn}}=\mathrm{O}_{\mathrm{i}(\mathrm{bhi})}^{\mathrm{pn}}+\mathrm{O}_{\mathrm{i}(\mathrm{bhr})}^{\mathrm{pn}}+\mathrm{O}_{\mathrm{i}(\mathrm{nbh})}^{\mathrm{pn}}
$$

Donde:

$\mathrm{O}_{\mathrm{i}}^{\text {pn }} \quad$ : Número total de viajes con propósito $\boldsymbol{p}$, producidos por usuarios de la categoría $\boldsymbol{n}$, en la zona $\boldsymbol{i}$.

$\mathrm{O}_{\mathrm{i}(\text { bhi })}^{\mathrm{pn}}:$ Número de viajes basados en el hogar de ida (bhi), para la misma clasificación anterior.

$\mathrm{O}_{\mathrm{i}(\mathrm{bhr})}^{\mathrm{pn}}$ : Número de viajes basados en el hogar de retorno $(b h r)$, para la misma clasificación anterior.

$\mathrm{O}_{\mathrm{i}(\mathrm{n} n h)}^{\mathrm{pn}}:$ Número de viajes no originados en el hogar (nbh), para la misma clasificación anterior.

Esta distinción es metodológicamente importante por las siguientes razones: en primer lugar, porque la importancia de cada tipo de viaje depende del período de modelación; es así como los viajes basados en el hogar de ida se realizan principalmente en el período punta de la mañana. En segundo lugar, la generación de los viajes basados en el hogar de ida se explica por las variables socioeconómicas asociadas al hogar del viajero. Por su parte, la generación de viajes no basados en el hogar y basados en el hogar de retorno puede ser explicada por aquellas variables asociadas a las actividades que se desarrollan en las zonas. Estos dos últimos tipos de viajes son importantes en el período fuera de punta.

Para los viajes originados en el hogar, la metodología más utilizada se basa en la determinación de ciertas tasas de generación de viajes por hogar y en el conocimiento del número de hogares en una determinada zona. De acuerdo con la estratificación de la demanda que se ha discutido antes, dichas tasas deben ser conocidas dentro de cada período de análisis, para cada propósito de viaje y categoría del hogar. 


$$
\mathrm{O}_{\mathrm{i}(\text { bhi })}^{\mathrm{pn}}=\mathrm{H}_{\mathrm{i}}^{\mathrm{n}} * \mathrm{t}^{\mathrm{pn}}
$$

Donde:

$\mathrm{O}_{\mathrm{i}(\text { bhi) }}^{\mathrm{pn}} \quad$ : Número de viajes con propósito $\boldsymbol{p}$, generados por los hogares de la categoría $\boldsymbol{n}$ de la zona $\boldsymbol{i}$.

$\mathrm{H}_{\mathrm{i}}^{\mathrm{n}} \quad$ : Número de hogares de la categoría $\boldsymbol{n}$ en la zona $\boldsymbol{i}$.

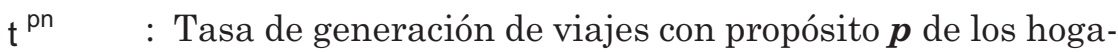
res de la categoría $\boldsymbol{n}$.

Este modelo requiere conocer el número de hogares por categoría en cada zona, lo cual debe ser determinado o estimado a partir de información socioeconómica. Además, es necesario conocer la distribución de hogares por categoría no solo en el año base de análisis; también se requiere la distribución futura de los hogares para cada uno de los cortes temporales.

Luego, el problema se reduce a encontrar las tasas de generación de viajes para cada categoría de hogar y propósito. Esta tarea habitualmente se realiza con los denominados modelos de análisis por categorías, los cuales determinan las tasas de generación buscadas a partir de una muestra de hogares, simplemente dividiendo para cada categoría ingreso-tasa de motorización el número de viajes observados de un propósito por el número de hogares en la muestra.

A pesar de su popularidad y sus ventajas teóricas, la aplicación práctica de este modelo suele presentar problemas importantes. El primero de ellos se relaciona con la representatividad de las tasas calculadas para las categorías extremas, donde el número de hogares en la muestra puede ser demasiado pequeño (por ejemplo, hogares de bajos ingresos con dos o más autos); otro problema común es la obtención de tasas contraintuitivas. ${ }^{4}$

4 La palabra contraintuitiva debe entenderse en el sentido de que los resultados obtenidos son contrarios a lo que el analista esperaría de acuerdo con su experiencia. Se esperaría que a medida que aumenta el ingreso del hogar aumente su tasa de generación de viajes. La misma tendencia se esperaría respecto a la tasa de motorización. 
Una variación del modelo anterior es el llamado modelo de análisis de clasificación múltiple (ACM). Este modelo, que es una extensión del análisis de varianza Anova, se ha demostrado teórica y prácticamente muy útil para calcular tasas de generación de viajes. Además permite superar casi todas las falencias del análisis por categoría tradicional.

La generación de viajes basados en el hogar, de retorno (muy raros en el período punta mañana y más frecuentes en el período fuera de punta), debe ser modelada con regresión lineal múltiple (RLM) en el ámbito zonal, dado que en este caso el método ACM es inaplicable, puesto que el origen del viaje no es el hogar y, por ello, no es lícito considerar el número de hogares como variable explicativa.

En consecuencia, este tipo de viajes será función de variables asociadas con el uso de suelos y las actividades de una zona. En este sentido, las variables explicativas del modelo de RLM serán casi las mismas que utilizan los modelos de RLM de atracción de viajes, que se discutirán en el acápite siguiente (exceptuando el número de hogares por zona).

Sin embargo, a diferencia de los modelos de atracción de viajes, la generación de viajes debe clasificarse por categoría de demanda, de manera que se plantean dos alternativas: una consiste en calibrar un modelo RLM por categoría, mientras que la segunda consiste en calibrar un modelo RLM que no distingue categorías (modelo conjunto) y aplicar posteriormente factores que representen adecuadamente la proporción de cada tipo de usuarios.

La primera alternativa es la más deseable; sin embargo, su utilización y grado de confiabilidad está limitada por el número de viajes observados en cada categoría de demanda. Es por ello que ese método puede presentar problemas de calibración y probablemente sea difícil obtener modelos de RLM estadísticamente robustos. La segunda alternativa requiere conocer el porcentaje de viajes basados en el hogar de retorno, generados por zona de acuerdo con la clasificación de demanda. Esta información se obtendrá a partir de la encuesta viajepersona.

Finalmente, es necesario señalar que tal como antes se indicara, en el período punta de la mañana, este tipo de viajes son muy raros, por lo que una posibilidad para incluirlos será amplificar los viajes de ida generados en el hogar para cada zona (modelados con tasas ACM se- 
gún se discutió antes), por un cierto porcentaje que represente los viajes basados en el hogar de retorno. Ciertamente, este es un procedimiento arbitrario que debe entenderse como un recurso extremo.

La generación de viajes no basados en el hogar debe ser modelada con regresión lineal múltiple (RLM) a nivel zonal, puesto que en este caso el método ACM es inaplicable.

La generación de estos viajes será función de variables asociadas con el uso de suelos y las actividades de una zona. En este sentido, las variables explicativas del modelo RLM de generación de viajes serán básicamente las mismas que se utilizan en los modelos RLM de atracciones de viajes que se discutirán en el acápite siguiente.

No obstante, a diferencia del caso de las atracciones de viajes, la generación de viajes debe ser clasificada por categoría de demanda, de manera que debe calibrarse un modelo RLM para cada categoría. Ello puede presentar problemas de calibración, puesto que especialmente en el período punta de la mañana, el número de viajes no originados en el hogar puede ser muy pequeño.

Si a lo anterior se agrega que este escaso número de viajes deben ser diferenciados por propósito y categoría, se entiende que probablemente sea difícil obtener modelos RLM estadísticamente robustos.

En el caso de que se presente este problema, una posibilidad será amplificar los viajes originados en el hogar en una zona (modelados con ACM según se discutió antes) por un cierto porcentaje que represente a los viajes no originados en el hogar, respecto al total de viajes producidos en una zona. Ciertamente este es un procedimiento arbitrario, que debe ser entendido como recurso extremo.

Además, se requiere conocer (o estimar) el porcentaje de viajes originados y no originados en el hogar por cada zona, propósito y categoría.

Para efectos de calibración de modelos de atracción de viajes, es recomendable considerar al menos dos alternativas:

- Una aplicable a viajes atraídos basados en el hogar de ida (bhi) y viajes no basados en el hogar (nbh).- Para estos dos casos, las variables explicativas corresponden normalmente a equipamientos por zona, dedicados a cada actividad y no los hogares (recuérdese que ninguno de estos viajes tiene por destino el hogar). Tal como se ha 
discutido antes respecto a la atracción de viajes, si se exceptúan los métodos de regresión lineal, prácticamente no existen opciones metodológicas de análisis. Por lo tanto, un modelo de este tipo debe ser calibrado a nivel zonal para cada propósito y período de análisis definido, utilizando técnicas de regresión lineal múltiple (RLM).

- La otra es aplicable para modelar la atracción de viajes basados en el hogar de retorno (bhr).- En este caso, dado que el destino del viaje es el hogar, la única variable explicativa posible será el número de hogares por zona. En este caso, es posible utilizar la técnica de regresión lineal simple (RLS) y también considerar modelos de tasas ACM de atractividad para modelar estos viajes. Es interesante comparar los resultados de la modelación utilizando RLM con el modelo de tasas ACM obtenido, dado que ambos utilizan la misma variable explicativa.

La distinción antes indicada es recomendable para los modelos correspondientes al período fuera de punta, puesto que en dicho período se verifica un número relevante de viajes basados en el hogar de retorno (bhr). Tal como antes se discutiera, para el caso del período punta mañana, los viajes de este tipo son escasos, por lo que no es recomendable su separación. Evidentemente, la atracción total de viajes corresponderá a la suma de los resultados de ambos modelos.

El modelo general de regresión lineal múltiple (RLM) tiene la forma típica siguiente:

$$
D_{j}^{p}=\theta_{0}+\sum_{k} \theta_{k}{ }^{*} X_{j k}+E_{j}
$$

Donde:

$$
\begin{array}{ll}
D_{\mathrm{j}}^{\mathrm{p}} & : \text { Número de viajes con propósito } \boldsymbol{p} \text { atraídos por la zona } \boldsymbol{j} . \\
\theta_{\mathrm{k}} & : \text { Parámetros de calibración. } \\
\mathrm{X}_{\mathrm{jk}} & : \text { Variables explicativas zonales. } \\
\mathrm{E}_{\mathrm{j}} & : \text { Error de la estimación para la zona } \boldsymbol{j} .
\end{array}
$$

Estos modelos estiman el número de viajes atraídos por una zona, suponiendo una relación lineal de esta variable con ciertas caracterís- 
ticas del área. En general, estas características se refieren al equipamiento existente en el lugar, en términos de las actividades relevantes según propósito de viaje:

- Viajes con propósito de trabajo.-Atraídos por las actividades que ofrecen empleos. Las más relevantes son el comercio, los servicios y la industria.

- Viajes con propósito de estudio.- Atraídos por la presencia de establecimientos educacionales (número de matrículas por nivel de educación: básica, media y superior).

- Viajes con otros propósitos.- Corresponden a los viajes de compras, diligencias y salud, entre otros. Las actividades relevantes serán el comercio, los servicios y las atenciones de salud. Además, para incluir el efecto de los viajes con motivos sociales suele incluirse como variable explicativa el total de hogares existente en una zona.

Idealmente, el modelo debería determinar el número de viajes atraídos por zona, no solo para cada período y propósito, sino también para cada categoría de demanda. Desafortunadamente, en el caso de las atracciones de viajes, dado que se desconocen otras formas de entender el fenómeno de forma más desagregada, habitualmente se considera cada zona y sus características globales como unidad de análisis del modelo, lo cual hace muy difícil clasificar las atracciones por categoría de demanda.

En otras palabras, las atracciones de viajes son modeladas a nivel zonal, lo que normalmente implica que solo serán explicadas por período y propósito, pero no por categoría socioeconómica. En el contexto de ambos modelos de transporte, este será también el modus operandi adoptado.

Los modelos de distribución agregados de viajes se usan para predecir flujos entre zonas de origen y destino, es decir que permite estimar el número de viajes realizados durante un determinado período entre las distintas zonas del sistema analizado.

En la figura 7 se aprecia un esquema que muestra los datos de entrada, las técnicas analíticas y los resultados obtenidos en la aplicación del modelo de distribución de viajes. 
Figura 7

Esquema del modelo de distribución de viajes

\section{Datos de entrada}

Modelo

Técnica analítica

- $\mathrm{O}_{\mathrm{i}}, \mathrm{D}_{\mathrm{j}}$

- Costos generalizados de viaje $\mathrm{C}_{\mathrm{ij}}$

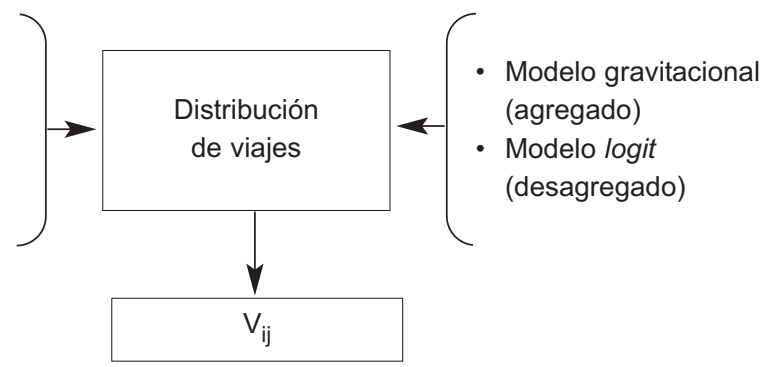

$V_{i}$ : Total viajes generados en la zona i atraídos por la zona $\mathrm{j}$

Elaboración propia.

Existen varios enfoques de modelación, la mayoría modelos matemáticos, para estimar la matriz de distribución de viajes dentro de una determinada área de estudio:

- Encuestas de viaje.- Muchas celdas vacías y muy costosas.

- Métodos de factor de crecimiento.- Consideran que se dispone de una matriz de viajes obtenida de un estudio previo. Se emplea el método de factor uniforme, en el cual todos los elementos de la matriz crecen a la misma tasa o el método de factores de crecimiento acotados, en el cual cada celda de la matriz crece de acuerdo con información sobre la generación y atracción de viajes de la zona. Estos modelos poseen una rápida convergencia y son razonables en áreas estables y en análisis de corto plazo, permitiendo los análisis de sensibilidad. En contraparte son resultados menos exactos e inelásticos ante cambios en la red de transporte.

- Modelo de gravedad.- Considera que el número de viajes se incrementa a medida que es mayor la población de las zonas y disminuyen los viajes en función de la distancia que las separa de la zona centro. Este modelo considera los impactos de los niveles de servicio de las redes de transporte, replica mejor los resultados observados y presenta mejor ajuste estadístico. 
A continuación, en la figura 8 se presenta un esquema de la construcción de la matriz origen-destino, que es el producto del modelo de distribución de viajes.

Figura 8

Construcción de la matriz origen destino (matriz OD)

\begin{tabular}{|c|c|c|c|c|c|c|}
\hline $\mathrm{i} / \mathrm{j}$ & zona 001 & zona 002 & $\ldots$ & zona 426 & zona 427 & Total $\left(\mathrm{O}_{\mathrm{i}}\right)$ \\
\hline \multicolumn{7}{|l|}{ zona 001} \\
\hline \multicolumn{7}{|l|}{ zona 001} \\
\hline$\ldots$ & & & & $\mathrm{V}_{\mathrm{ij}}$ & & $\mathrm{O}_{\mathrm{i}}=\sum_{\text {fila } \mathrm{i}}$ \\
\hline \multicolumn{7}{|l|}{ zona $\mathrm{n}$} \\
\hline Total $\left(D_{j}\right)$ & & & & $\mathrm{D}_{\mathrm{j}}=\underset{\text { columna } \mathrm{j}}{=}$ & & \\
\hline \multicolumn{4}{|c|}{ Vector de atracción de viajes } & \multicolumn{2}{|c|}{ Vector de producción de viajes } & $\leftarrow$ \\
\hline
\end{tabular}

Elaboración propia.

Los vectores de producción y atracción son resultados provenientes de la encuesta Viaje-Persona, expandidos y ajustados de acuerdo a los modelos de generación y atracción de viajes; luego se calculan los valores de las celdas de la matriz mediante los modelos de distribución.

Los modelos de distribución de viajes que es posible aplicar pueden diferenciarse en dos tipos:

- Modelos de viajes interzonales.- Para los viajes entre zonas de origen y destino distintas se planteó el siguiente modelo:

Viajes interzonales: $V_{i j}=O_{i}\left[\frac{D_{j}{ }^{*}\left(\text { Dist }_{i j}\right)^{a}}{\sum_{j} D_{j}{ }^{*}\left(\text { Dist }_{i j}\right)^{a}}\right]$ 
Donde:

$\mathrm{V}_{\mathrm{ij}} \quad$ : Viajes originados en la zona $\boldsymbol{i}$ con destino en la zona $\boldsymbol{j}$.

$\mathrm{O}_{\mathrm{i}} \quad$ : Viajes generados en la zona $\mathrm{i}$.

$D_{j} \quad$ : Viajes atraídos a la zona $\mathrm{j}$.

Dist $_{\mathrm{ij}}$ : Distancia de tiempo (horas), distancia medida entre los centros de cada zona, entre la zona $\boldsymbol{i}$ y $\boldsymbol{j}$.

a : Parámetro.

- Modelos de viajes intrazonales.- Para los viajes que tienen por origen y destino la misma zona se plantea el siguiente modelo:

$$
\text { Viajes intrazonales: } V_{i j}=K *\left(O_{i}\right)^{a *}\left(D_{i}\right)^{b *}\left(L_{i}\right)^{c *}\left(D_{i s t}\right)^{d}
$$

Donde:

$\mathrm{V}_{\mathrm{ii}}$ : Viajes dentro de la zona $\boldsymbol{i} . \quad \mathrm{O}_{\mathrm{i}}$ : Viajes generados en la zona $\boldsymbol{i}$.

Di: Viajes atraídos a la zona $\boldsymbol{i} . \quad \mathrm{L}_{\mathrm{i}}$ : Área $\left(\mathrm{Km}^{2}\right)$ de la zona $\boldsymbol{i}$.

Dist: $_{i}$ Variable falsa. $\mathrm{K}, \mathrm{a}, \mathrm{b}, \mathrm{c}, \mathrm{d}$ : Parámetros.

Los modelos planteados, interzonales e intrazonales, se fundamentan en una función de impedancia; para el presente caso, la distancia entre los centros de cada zona. Esta función de impedancia puede ser de diversos tipos. La función de impedancia que presenta los mejores resultados son las funciones basadas en los costos generalizados. Como esta función no presenta dificultades para tratar los viajes interzonales e intrazonales, hace posible plantear un único modelo de distribución. El modelo de distribución modificado quedaría expresado de la siguiente forma:

$$
V_{i j}=O_{i}\left[\frac{D_{j}{ }^{*} f\left(C_{i j}\right)}{\sum_{j} D_{j}^{*} f\left(C_{i j}\right)}\right]
$$

Donde:

$\mathrm{f}\left(\mathrm{c}_{\mathrm{ij}}\right)$ : Función de impedancia entre las zonas $\boldsymbol{i}$ y $\boldsymbol{j}$. 
Las funciones de impedancia propuestas para la calibración son las siguientes:

- $f\left(C_{i j}\right)=e^{-\lambda c_{i j}}$

Exponencial

- $f\left(C_{i j}\right)=(C i j)^{-\beta}$ Potencial

- $f\left(C_{i j}\right)=(C i j)-\beta * e^{-\lambda C_{i j}}$ Combinada

De acuerdo con estudios realizados, la función de impedancia que mejor se ajusta es la de tipo combinada.

Los costos generalizados son calculados de la siguiente forma:

$$
C_{i j}^{k}=t v_{i j}^{k}+t e_{i j}^{k *} \text { pwait }+t_{i j}^{k *} \text { pwalk }+\frac{t a_{i j}^{k}}{v t}+p t t^{k}
$$

Donde:

$\mathrm{C}_{\mathrm{ij}}^{\mathrm{k}} \quad$ : Coto generalizado de viaje en el modo $\boldsymbol{k}$ entre las zonas $\boldsymbol{i}$ y $\boldsymbol{j}$.

$\mathrm{tv}_{\mathrm{ij}}^{\mathrm{k}} \quad$ : Tiempo de viaje en el modo $\boldsymbol{k}$ entre las zonas $\boldsymbol{i}$ y $\boldsymbol{j}$.

$t e_{i j}^{k} \quad$ : Tiempo de espera en el modo $\boldsymbol{k}$ entre las zonas $\boldsymbol{i}$ y $\boldsymbol{j}$.

pwait : Ponderador del tiempo de espera.

$\mathrm{tc}_{\mathrm{ij}}^{\mathrm{k}} \quad$ : Tiempo de caminata en el modo $\boldsymbol{k}$ entre las zonas $\boldsymbol{i}$ y $\boldsymbol{j}$.

pwalk : Ponderador del tiempo de caminata.

$\mathrm{ta}_{\mathrm{ij}}^{\mathrm{k}} \quad$ : Tarifa en el modo $\boldsymbol{k}$ entre las zonas $\boldsymbol{i}$ y $\boldsymbol{j}$.

vt : Factor de conversión de unidades monetarias a unidades de tiempo.

$\operatorname{ptr}^{\mathrm{k}} \quad$ : Penalidad de trasbordo en el modo $\boldsymbol{k}$.

Los modelos de selección modal son utilizados para analizar y predecir la elección que los individuos harán al escoger los modos de transporte que son utilizados para cada tipo particular de viaje. Generalmente, el objetivo es predecir la proporción o el número de viajes hechos en cada modo, principalmente predecir la proporción de los viajes atraídos por el transporte público. 
En la figura 9 se aprecia un esquema que muestra los datos de entrada, las técnicas analíticas y los resultados obtenidos en la aplicación del modelo de repartición modal de viajes.

\section{Figura 9}

\section{Esquema del modelo de partición modal de viajes}

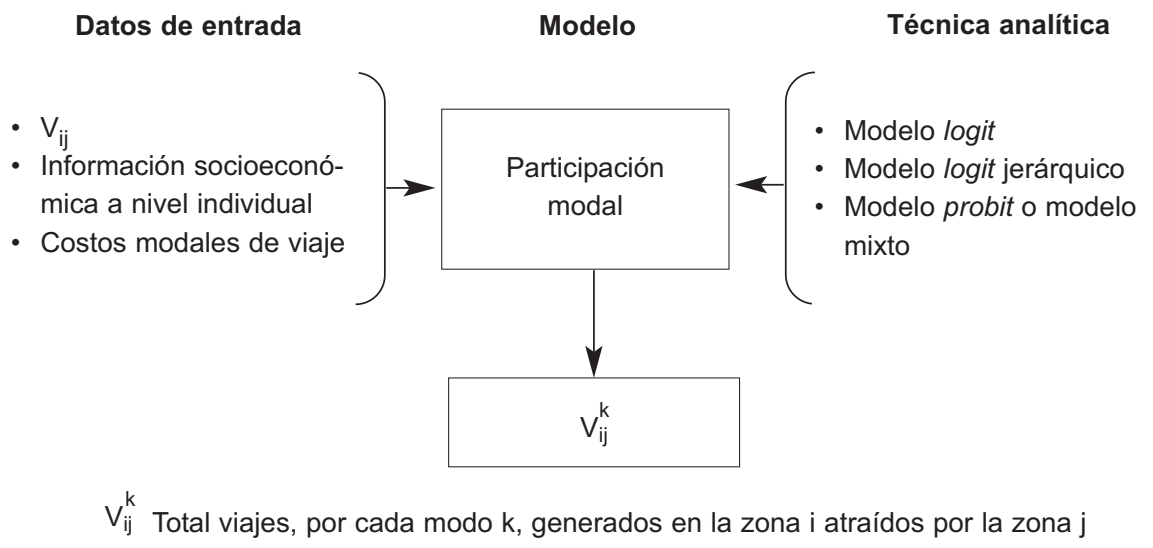

Elaboración propia.

Para la repartición modal de viajes se ha utilizado el modelo multinomial logit en base a la función de utilidad asociado a cada uno de los modos de viaje:

$$
\begin{aligned}
& \mathrm{U}_{\text {auto_privado }}=\alpha_{1}+\beta_{1}{ }^{*} \text { tiempo de viaje }+\beta_{2} \text { - Costo de viaje } \\
& \begin{aligned}
& \mathrm{U}_{\text {taxi }}= \alpha_{2}+\beta_{1}{ }^{*} \text { tiempo de viaje }+\beta_{2}{ }^{*} \text { Costo de viaje }+\beta_{3}{ }^{*} \text { tiempo de espera } \\
& \mathrm{U}_{\text {bus }}= \alpha_{1}+\beta_{1}{ }^{*} \text { tiempo de viaje }+\beta_{2}{ }^{*} \text { Costo de viaje }+\beta_{4}{ }^{*} \text { tiempo de espera }+ \\
& \beta_{1}{ }^{*} \text { tiempo de transferencia } \\
& \mathrm{U}_{\text {bus_troncal }}=\alpha_{4}+\beta_{1}{ }^{*} \text { tiempo de viaje }+\beta_{2}{ }^{*} \text { Costo de viaje }+\beta_{5}{ }^{*} \text { tiempo de espera } \\
&+\beta_{8}{ }^{*} \text { tiempo de transferencia } \\
& \mathrm{U}_{\text {tren }}=\beta_{1}{ }^{*} \text { tiempo de viaje }+\beta_{2}{ }^{*} \text { Costo de viaje }+\beta_{6}{ }^{*} \text { tiempo de espera }+ \\
& \beta_{9}{ }^{*} \text { tiempo de transferencia }
\end{aligned}
\end{aligned}
$$


Donde:

$\mathrm{U}_{\mathrm{i}}$ : Utilidad del modo i (automóvil privado, taxi, bus convencional, bus troncal y vía férrea).

$\mathrm{b}_{\mathrm{i}}$ : Coeficientes del modelo

$\mathrm{b}_{0}:$ Constante

Luego se aplica la siguiente fórmula:

$$
P_{i}=\frac{e^{u i}}{\sum e^{u j}}
$$

Donde:

$\mathrm{P}_{\mathrm{i}}$ : Probabilidad de escoger el modo i.

\section{BIBLIOGRAFÍA}

Barceló, J.; Grzybowska, H. y J. A. Orozco. "A simulation based decision support system for City logistics aplications". Congreso bianual de carácter internacional. Seattle, WA., 4-7 de noviembre del 2007.

Fernández Guell, José Miguel. Planificación de estrategias de ciudades. Barcelona: Gustavo Gili, S.A., 1997.

Galán González, José Raymundo. "Determinantes de la demanda por transporte público y privado en el área metropolitana de Monterrey”. Ciencia UANL. Vol. VIII, núm. 4. México: Universidad Autónoma de Nuevo León. Octubre-diciembre.

JICA. Plan Maestro de Transporte Urbano (3 volúmenes). Lima: Consejo de Transporte de Lima y Callao/Ministerio de Transporte y Comunicaciones/Agencia Internacional de Cooperación Japonesa.

Moller, Rolf. La alternativa para el transporte público colectivo en Colombia. Cali: Universidad del Valle, 2004. 
Ortúzar, Juan de Dios. Modelos de demanda de transporte. 2. ${ }^{a}$ edición. Santiago: Alfaomega/Universidad Católica de Chile, 2002.

Ortúzar, J. y G. Willumsen. Modelling transport. 3. ${ }^{\text {a }}$ edición. Londres: John Wiley, 2001.

Osses, M. y R. Fernández. "Transport and air quality in Santiago de Chile". Advances in city transport. Southampton: WIT Press, 2004 (en edición).

Sant'anna, José. Autobuses urbanos. Nueva York: Banco Interamericano de Desarrollo, 2002.

Vivas Motta, Marco Antonio. Tránsito y transporte público urbano en Brasil. Banco Interamericano de Desarrollo, 2002. 